\title{
Impedance based service life assessment of corroded structures with Cross correlation analysis
}

\author{
N. Naga Sai Pravallika ${ }^{l}$, Dr. V. Mallikarjuna Reddy ${ }^{2}$ and Dr. B. Siva Konda Reddy ${ }^{3}$. \\ ${ }^{1}$ M.Tech Scholar, Civil Engineering Department, GRIET, Hyderabad, Telangana, India. \\ ${ }^{2}$ Professor \&Head, Civil Engineering Department, GRIET, Hyderabad, Telangana, India. \\ ${ }^{3}$ Associate Professor, Civil Engineering Department, JNTUH, Hyderabad, Telangana, India.
}

\begin{abstract}
Electro mechanical impedance technique has garnered major significance in structural health monitoring field by integrating with information and sensing technology. Technical advancements in automated smart devices improved the diagnostic evaluation of this monitoring method by incorporating piezoelectric materials. The optimistic coupling property of these materials enhanced the life span of structural members by detecting damages at incipient stage. The intervention of piezoelectric transducers has created potential applications for impedance approach in assessing the structural performance with high feasibility. The present work aims at estimating the service life of simply supported smart beam using piezoelectric sensors in Abaqus Simulia software. Corrosion is deployed at a uniform rate in reinforced concrete beam with impressed current flow and the loss in diameter of rebar is calculated using Faraday's electrochemical equation. With frequency domain based impedance technique numerical analysis is conducted on the modeled beams by exciting the sensor with an external harmonic force and the output electric responses of different piezoelectric locations are captured. The steady state dynamic responses for different cases are compared and quantified with a statistical damage algorithm in MATLAB. The resulted cross correlation indices are analyzed to prevent further deterioration of the corroded beams by setting a limit value. The proposed simulation technology is capable of estimating the residual life span of damage structures with cross correlation analysis.

Keywords: SHM, Impedance technology, Piezoelectric sensor, Corrosion, Cross correlation index
\end{abstract}

\section{Introduction}

A recent study on the published literature inferred that service life prediction of structural members subjected to rebar corrosion remains at the parametric stage [1]. It is vital to perform intense research on perilous problems of reinforcement corrosion as it significantly affects the structural performance by reducing its durability. The premature deterioration of corroded structures typically begins with gradual penetration of chlorine and carbon dioxide from atmosphere into the concrete by breaking the impervious protective layer [2]. This intrusion creates an electrical potential difference with pore water as electrolyte leading to electrochemical corrosion of steel. In anodic regions, the surface atoms undergo oxidation and release electrons that combine with polarizer like acids, oxygen and moisture at the cathodic region to form hydroxyl ions. These ions travel along the electrolyte to combine with positively charged Ferrous ions and forms a mixture of stable Ferric hydroxides which by further oxidation converts into rust whose volume is six times more than the original steel rebar. As a result these end products exert radial thrust on the hardened concrete at the interface causing longitudinal cracking, delamination of concrete, pitting, excessive deflections and make the steel rebar frizzle by reducing its gross cross sectional area [3].

These detrimental agents will cause sudden collapse of the structure by decreasing bond strength, stiffness, load carrying capacity and ultimate strength of the spalled concrete [4]. As the structural integrity is affected with these aggressive effects, it is essential to treat corrosion in initial stages by removing the damaged concrete material, 
increasing the reduced steel area, cleaning and applying coating over the steel surface and covering with concrete cover of suitable thickness. All the above steps of treatment must be executed with utmost care because the repaired area in the presence of small contaminated concrete patch will become anodic and begin to corrode. Therefore it is imperative not only to repair the corroded material but also to prevent the entry of depassivating chemicals into the concrete by controlling with metallurgical methods, sacrificial coatings and cathode protection [5]. Rapid development in Nondestructive evaluation techniques enabled Electrical Half cell Potential method to estimate the corrosion activity in steel reinforcement [6]. This method is the most standard and quick test performed to determine the probability of corrosion by calculating the current densities with potential difference values driven by the electrodes of two half cells. The qualitative nature of this traditional method did not give any information about the corroded area location and severity rate as it depends on many external environmental factors [7]. The technical advancements in Structural Health Evaluating methods enhanced researchers to overcome the limitations of visual manual inspection and conventional damage measurement tests by providing reliable and accurate solutions [8,9].

SHM with the intervention of information and sensing technology has showed an excellent potential of monitoring the corrosion process continuously with various sensors from initial stages [10]. Among them Piezo ceramic materials have attracted a considerable amount of interest due to their easy installation, low cost, high feasibility and resistivity[11, 12]. The piezoelectric sensing system when driven by external electric field gets excited and produces mechanical vibrations which can be converted again into electrical responses [13,14]. This optimistic dual property of converting energies from one form to other implemented piezoelectric materials as sensors and actuators in impedance based approaches for generating high frequency waves $[15,16]$. The first one dimensional electrochemical impedance equation on 1D host structure was proposed in 1996[17] which enhanced the application of this technique in various fields for interpreting the structural changes [18]. The simulation technology with the instrumentation of sophisticated transducers is capable of conducting numerical computation analysis on three dimensional finite element models of complicated geometry [19].

The present paper focuses on estimating the residual service life of corroded beams with piezoelectric transducers by conducting EMI analysis [20,21]. Corrosion is simulated uniformly to the reinforced beams by applying a fixed amount of current for a specific varied duration and with Faraday's first law of electrolysis equation the rebar diameter loss is calculated.

$$
\mathrm{d}(\mathrm{t})=\mathrm{d}_{\mathrm{i}}-0.023 *\left(\mathrm{i}_{\text {cor }}\right) *(\mathrm{t})
$$

$\mathrm{d}(\mathrm{t})=$ reinforcement diameter at time $\mathrm{t}(\mathrm{mm})$

$\mathrm{d}_{\mathrm{i}}=$ initial reinforcement diameter at $\mathrm{t}=0(\mathrm{~mm})$ $\mathrm{i}_{\text {cor }}=$ current density $\left(\mathrm{mA} / \mathrm{cm}^{2}\right)$

$\mathrm{t}=$ applied current duration (days)

These beam models are electrically coupled with piezoelectric sensors in Abaqus Simulia software and excited with an external harmonic force to generate numerical finite element simulations [22]. The output responses in terms of sinusoidal vibration are captured and compared with healthy structure to anticipate the damage severity. The voltage variations are quantified in MATLAB by generating a simple statistical algorithm program for Cross Correlation index and these values are plotted against time to determine the duration up to which the corrosion affected structures remain in service condition [23]. A warning system is developed to prevent further deterioration by setting a limit value of 0.5 to Cc index [24].

\section{Numerical study}

In the current study, couple field numerical analysis is performed on a simply supported reinforced concrete beam using impedance based sensing technique. With an external current application corrosion is induced in the modeled beams by reducing the mass of the reinforcement. These corroded beams are analyzed to extract the dynamic responses using piezoelectric actuators and are further quantified to calculate the remaining life span.

Initially a three dimensional input file is created in part module of Abaqus software by selecting 8 noded and 2 noded solid extrusion elements for concrete beam and steel rebar. These elements are assigned with suitable material and geometrical properties in section property module as shown in Table 1 and Table 2 and assembled as a single database model by providing a clear cover of 30 mm using embedded constraint.

Table 1. Geometrical and Material properties of Concrete beam

\begin{tabular}{|l|l|}
\hline Length of beam & $6 \mathrm{~m}$ \\
\hline Cross section of beam & $300 \mathrm{~mm} \times 400 \mathrm{~mm}$ \\
\hline Grade of Concrete $\left(f_{c k}\right)$ & $25 \mathrm{~N} / \mathrm{mm}^{2}$ \\
\hline Density & $2400 \mathrm{~kg} / \mathrm{m}^{3}$ \\
\hline Hysteretic Damping ratio & 0.05 \\
\hline Modulus of elasticity & $2.5 \times 10^{10} \mathrm{~N} / \mathrm{m}^{2}$ \\
\hline Poisson's ratio & 0.15 \\
\hline
\end{tabular}

Table 2. Reinforcement properties and detailing

\begin{tabular}{|l|l|}
\hline Grade of Steel $\left(f_{y}\right)$ & $415 \mathrm{~N} / \mathrm{mm}^{2}$ \\
\hline Density & $7850 \mathrm{~kg} / \mathrm{m}^{3}$ \\
\hline $\begin{array}{l}\text { Modulus of } \\
\text { elasticity }\end{array}$ & $2.1 \times 10^{11} \mathrm{~N} / \mathrm{m}^{2}$ \\
\hline Poisson's ratio & 0.3 \\
\hline Main bars & 3 bars of $16 \mathrm{~mm}$ diameter \\
\hline Hanger bars & 2 bars of $12 \mathrm{~mm}$ diameter \\
\hline
\end{tabular}




\begin{tabular}{|l|l|}
\hline Stirrups & $\begin{array}{l}2 \text { legged } 8 \mathrm{~mm} \text { with 200mm } \\
\text { c/c spacing }\end{array}$ \\
\hline
\end{tabular}

A smart piezoelectric sensor of size $60 \mathrm{~mm} \times 60 \mathrm{~mm} \times$ $10 \mathrm{~mm}$ is modeled as a $3 \mathrm{D}$ couple element and attached to the top surface of the host structure in the interaction module using tie constraint. Critical impedance analysis is conducted on the beam by placing the sensor at two different positions from the right support as shown in the Figure 1, electrical and material properties of the PZT are mentioned in Table 3. After modeling, the elements are meshed independently in the mesh module with an appropriate mesh width of $0.01 \mathrm{~m}$ and $0.05 \mathrm{~m}$ for piezoelectric patch and beam

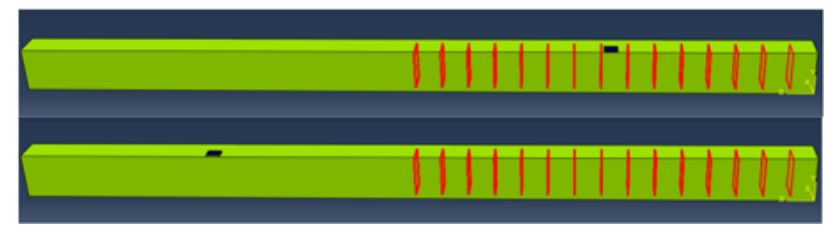

Fig.1. Piezoelectric patch locations for different cases

Table 3. Section properties of Piezoelectric sensor

\begin{tabular}{|l|l|}
\hline Relative Permittivity & PERX $=6.5$ \\
$\left(10^{-9} \mathrm{~F} / \mathrm{m}\right)$ & PERY $=6.5$ \\
& PERZ $=6.5$ \\
\hline Piezoelectric coupling & $\mathrm{d}_{31}=-5.2$ \\
coefficient $\left(10^{-10} \mathrm{C} / \mathrm{N}\right)$ & $\mathrm{d}_{33}=15.1$ \\
& $\mathrm{~d}_{15}=12.7$ \\
\hline Modulus of elasticity & $\mathrm{D}_{1111}=13.9$ \\
$\left(10^{10} \mathrm{~N} / \mathrm{m}^{2}\right)$ & $\mathrm{D}_{1122}=7.8$ \\
& $\mathrm{D}_{2222}=13.9$ \\
& $\mathrm{D}_{1133}=7.4$ \\
& $\mathrm{D}_{2233}=7.4$ \\
& $\mathrm{D}_{3333}=11.5$ \\
& $\mathrm{D}_{1212}=3.05$ \\
& $\mathrm{D}_{1313}=2.56$ \\
\hline Density $\left(\mathrm{kg} / \mathrm{m}^{3}\right)$ & 7500 \\
\hline
\end{tabular}

\begin{tabular}{|l|c|}
\hline Location & Case $1:$ PZT placed at \\
& $1.5 \mathrm{~m}$ from right end \\
& Case $2:$ PZT placed at \\
& $4.5 \mathrm{~m}$ from right end \\
\hline
\end{tabular}

The embedded steel bars of the healthy beam are subjected to corrosion at a uniform rate by inducing current density and the material loss in the rebar is calculated using electrochemical equation of Faraday. For the present work five stages are considered by increasing the duration of the applied current from 20 days to 100 days with current density of $5 \mathrm{~mA} / \mathrm{cm}^{2}$ and the diameter loss in the reinforcement of partially corroded beam in each stage is represented in the Table 4 . These beams are numerically modeled in the preprocessing stage with different corrosion rates and discretized to perform finite element analysis.

Firstly the dynamic features like mode shapes and natural frequencies are extracted from the modeled beams in the step module by conducting frequency analysis as shown in the Figure 2 and this data will act as a pre requisite tool to conduct harmonic analysis in the next step. These beams are excited by applying a voltage of $1 \mathrm{~V}$ to the surface bonded piezoelectric transducers in the initial boundary conditions and the output electrical responses in the frequency range $20-30 \mathrm{~Hz}$ are captured. In the second step dynamic implicit analysis is performed by actuating the piezoelectric with a periodic force of $F=1.5 \sin (25 \pi \mathrm{t})$ for one second time duration with a step size of 100 and the voltage responses with respective to natural frequency and time are recorded from the output field manager of visualization module as shown in the Figure 3 .

Table 4. Rebar diameter for different corrosion stages

\begin{tabular}{|c|c|c|c|c|}
\hline Corrosion stages in steel & Current density & Duration(days) & Rebar diameter & \multirow[t]{2}{*}{ Representation } \\
\hline \begin{tabular}{l|l} 
Mode & Mode
\end{tabular} & applied(mA/em²) & Nattric & equensym & \\
\hline 1 stage of corrosion & 5 & 20 & 3.2 & S1 \\
\hline $2^{\text {nd }}$ stage of corrosion & 5 & 40 & 6.4 & S2 \\
\hline $3^{\text {rd }}$ stage of corrosion & 5 & 60 & 9.6 & S3 \\
\hline $4^{\text {th }}$ stage of corrosion & 5 & 80 & 12.8 & S4 \\
\hline $5^{\text {th }}$ stage of corrosion & 5 & 100 & 16 & S5 \\
\hline
\end{tabular}

Table 5. Natural frequency of corroded beam at different stages 


\begin{tabular}{|l|l|c|c|c|c|c|c|}
\hline & & Healthy & S1 & S2 & S3 & S4 & S5 \\
\hline 1 & Lateral bending & 15.417 & 15.256 & 15.228 & 15.203 & 15.185 & 15.179 \\
2 & Transverse bending & 25.827 & 24.992 & 24.923 & 24.861 & 24.791 & 24.712 \\
3 & Lateral bending with two nodes & 51.982 & 51.639 & 51.547 & 51.469 & 51.414 & 51.394 \\
4 & Twisting & 65.124 & 65.309 & 65.078 & 64.901 & 64.786 & 64.747 \\
5 & Transverse bending with two & 65.783 & 65.516 & 65.464 & 65.382 & 65.289 & 65.247 \\
\hline
\end{tabular}

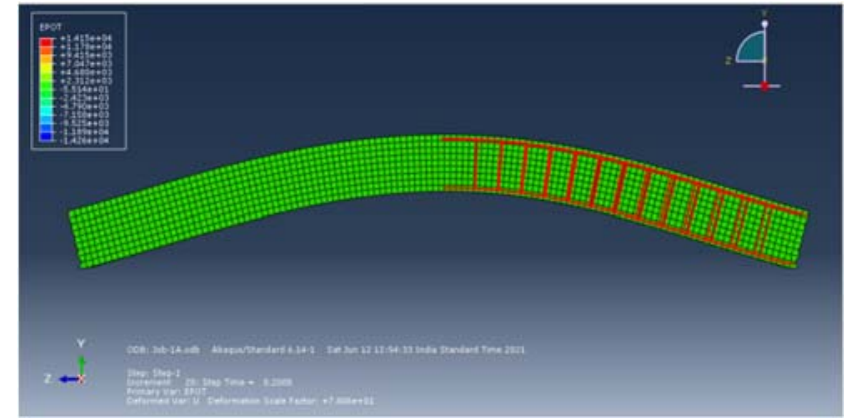

Fig.2. Corroded beam under modal analysis

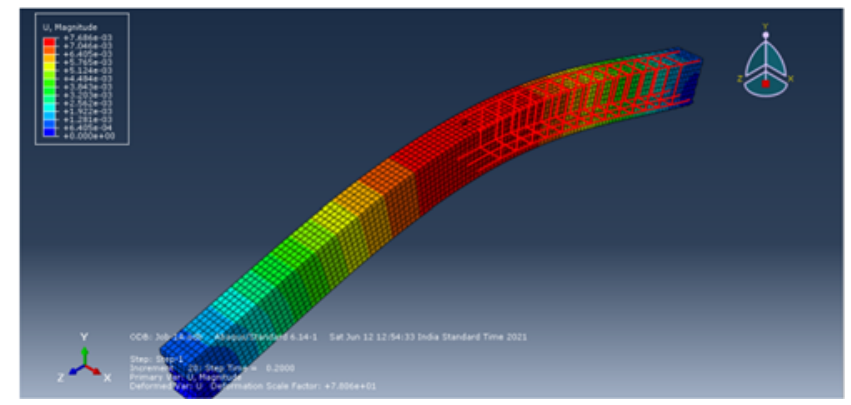

Fig.3. Corroded beam under harmonic analysis

The sinusoidal responses from different sensor locations for various corrosion stages are captured and analyzed to estimate the damage severity. These signals are further cross correlated in the data acquisition system of MATLAB with damage quantification index as

$$
\mathrm{Cc}=\frac{\left(\frac{1}{\mathrm{~N}}\right) \Sigma_{\mathrm{i}=1}^{\mathrm{N}}\left(\mathrm{H}_{\mathrm{i}}-\overline{\mathrm{H}}\right)\left(\mathrm{C}_{\mathrm{i}}-\overline{\mathrm{C}}\right)}{\sigma_{\mathrm{H}} \sigma_{\mathrm{C}}}
$$

where $\mathrm{H}$ represents healthy beam signal and $\mathrm{C}$ represents Corroded beam signal

\section{Results and Discussions}

\subsection{Frequency analysis}

With frequency analysis, the first five modal shape parameters are extracted for different corrosion stages as shown in the Table 5 and in each stage the resonant frequency of the corroded beam is compared with the natural frequency of healthy beam. From Figure 4 it is observed that resonating frequency of the beams got reduced with increase in corrosion rate from $\mathrm{S} 1$ to $\mathrm{S} 5$ due to larger reduction in stiffness value than the mass.

\subsection{Harmonic analysis}

A periodic sinusoidal load of specific harmonic frequency is generated to perform Linear Perturbation analysis and the mechanical vibrations of the beam are captured by the piezoelectric in the form of electrical signal. In harmonic analysis two cases are considered by placing the sensor in corroded and non corroded area at a distance of $1.5 \mathrm{~m}, 3 \mathrm{~m}$ from right support. The frequency vibrations of the corroded beams in terms of electrical potential for five different stages S1, S2, S3, S4 \& S5 with various diameter reduction rates are analyzed and compared for two different locations of PZT as shown in the Figures $5,6,7,8 \& 9$.

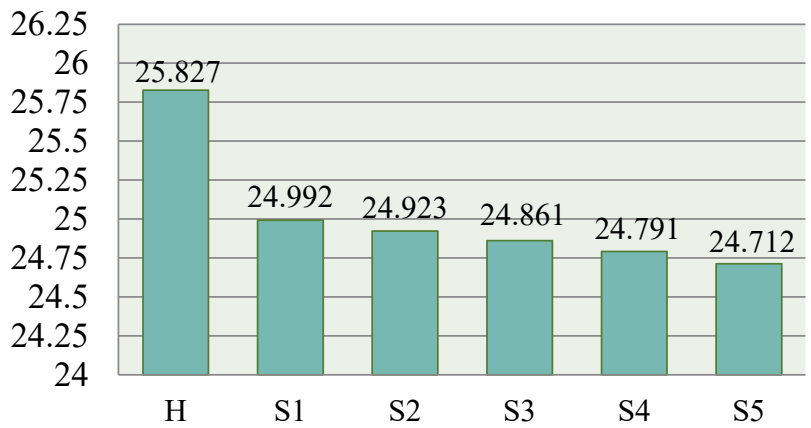

Fig.4. Natural frequency of beam for different cases

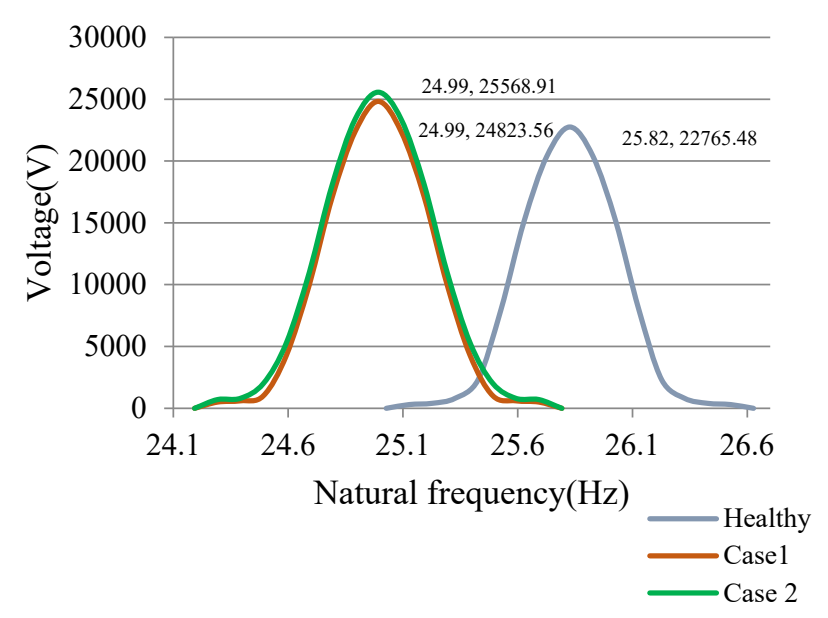


Fig.5. Frequency response of corroded beam in $1^{\text {st }}$ stage

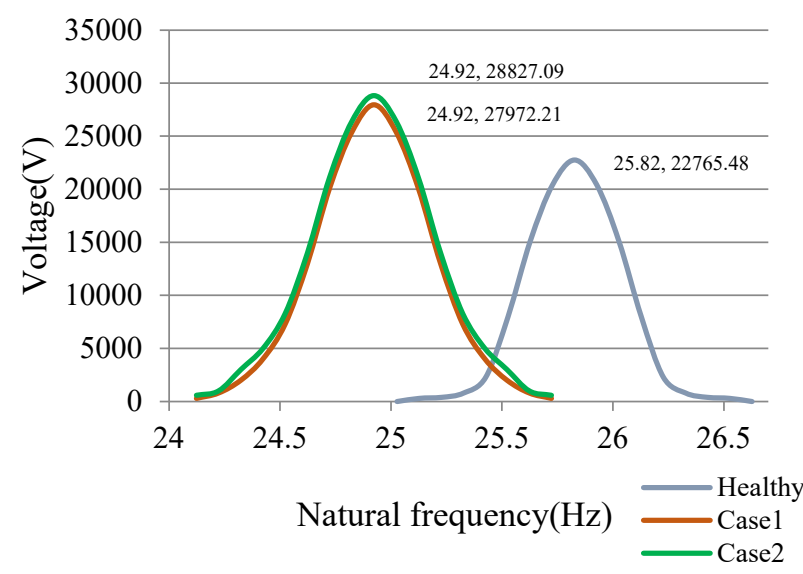

Fig.6. Frequency response of corroded beam in $2^{\text {nd }}$ stage
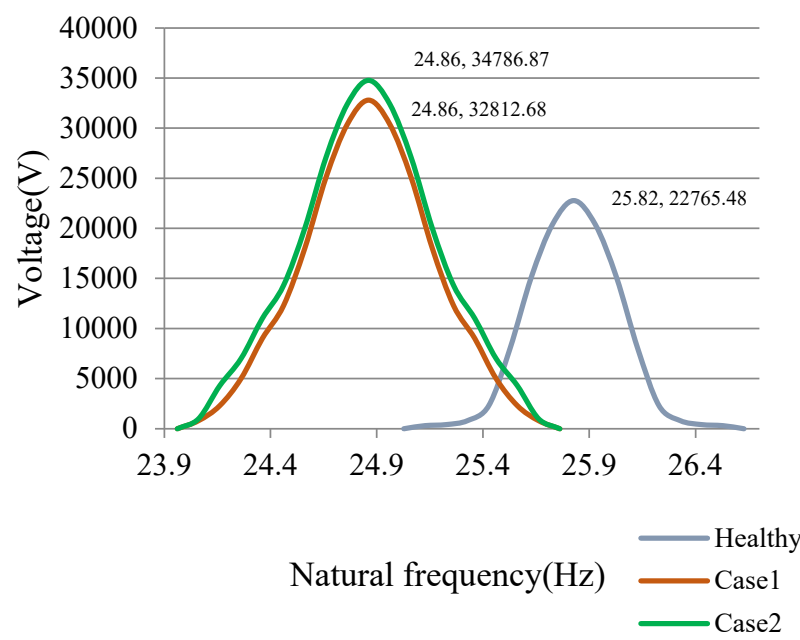

Fig.7. Frequency response of corroded beam in $3^{\text {rd }}$ stage

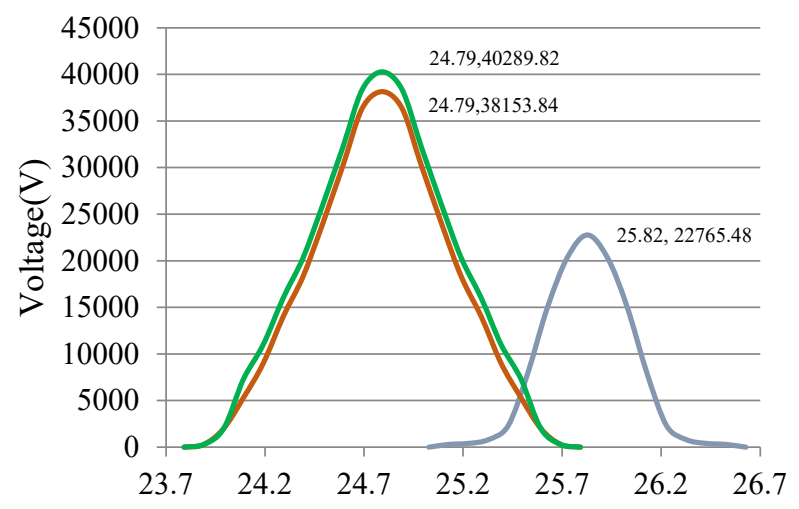

Natural frequency $(\mathrm{Hz}) \longrightarrow$ Healthy Case 2
Fig.8. Frequency response of corroded beam in $4^{\text {th }}$ stage

\begin{tabular}{|c|c|c|}
\hline Corrosion Stages & Case 1 & Case 2 \\
\hline S1 & 0.8965 & 0.9342 \\
\hline S2 & 0.7341 & 0.8529 \\
\hline S3 & 0.5978 & 0.6706 \\
\hline S4 & 0.3579 & 0.4628 \\
\hline S5 & 0.1231 & 0.2921 \\
\hline
\end{tabular}

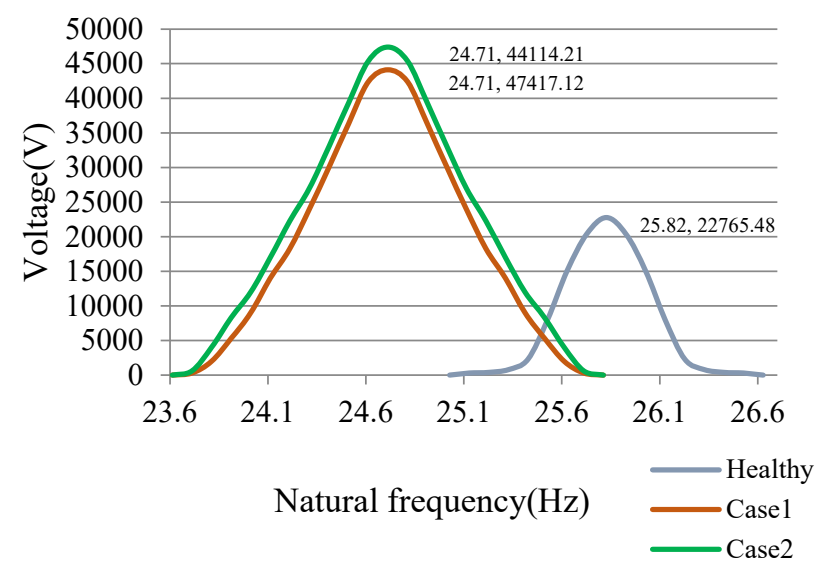

Fig.9. Frequency response of corroded beam in $5^{\text {th }}$ stage

With time domain harmonic analysis, the steady state response of voltage with respect to time is recorded for all the cases and using cross correlation method the damage severity is determined by comparing and quantifying the voltage of corroded signal with healthy signal using statistical index as shown in Table 6.

Table 6. Cc values for different sensor locations

From the above graphs, it is noticed that with increase in corrosion rate from Stage 1 to Stage 5 the amplitude of electrical voltage signal got increased with leftward shift of natural frequency. By comparing the results of sinusoidal responses of numerical analysis in both the cases for all the stages it is found that the sensor that is located near to the damaged region has shown a higher peak value of voltage than the other. Moreover from the Table 6 it is noticed that the PZT patch in Case 1 has recorded a less damage index value than the other sensor in Case 2. So to estimate the service life of corroded members the cross correlation values of piezoelectric 
sensor that is near to the damage is considered. A graph is plotted between the extracted Cc values of the piezoelectric in corroded area with respect current density duration as shown in Figure 10.

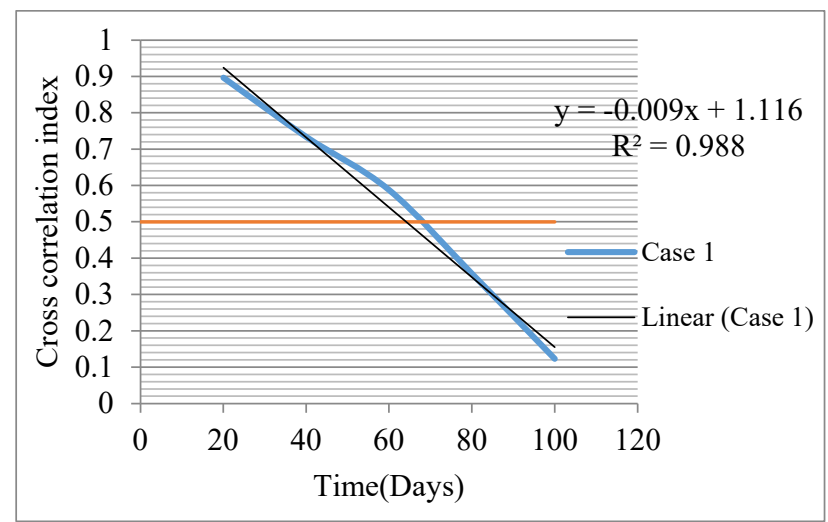

Fig.10. Cross correlation index vs Duration for Case1

From the graph the service life of the different staged corroded beam is predicted by applying linear regression. As 0.5 is taken as limiting value Cc index, the point where linear trend meets the limiting axis is considered. For the present study, beams will take 68 days to become out of service after corrosion initiation.

\section{Conclusions}

1. The simulation results of proposed technique demonstrated the variation in structural behaviour with corroson by measuring steady state dynamic responses of piezoelectric patches with couple field finite element analysis.

2. Quantitative evaluation of the present numerical study is achieved by performing computation analysis with statistical damage algorithms of MATLAB.

3. This localization impedance concept of damage assessment with piezoelectric transducers enhanced the structural integrity by incorporating advanced data acquistion systems.

\section{References}

1. A. Ranjith, K. B. Rao and K. Manjunath, Evaluating the effect of corrosion on service life prediction of $\mathrm{RC}$ structures-A parametric study. International Journal of Sustainable Built Environment, Vol. 5, No. 2, pp. 587-603, (2016).

2. B. Shi and G. F. Zhao, Reliability-based service life prediction of steel-corroded concrete structures, Journal-Dalian University of Technology, Vol. 47, No. 1, pp. 61, (2007).

3. J. Cao, L. Liu and S. Zhao, Relationship between Corrosion of Reinforcement and Surface Cracking
Width in Concrete, Advances in Civil Engineering, (2020).

4. K. Bhargava, A. K. Ghosh, Y. Mori and S. Ramanujam, Corrosion-induced bond strength degradation in reinforced concrete-Analytical and empirical models, Nuclear Engineering and Design, Vol. 237, No. 11, pp. 1140-1157, (2007).

5. M. Ormellese, M. Berra, F. A. Bolzoni and T. Pastore, Corrosion inhibitors for chlorides induced corrosion in reinforced concrete structures, Cement and concrete research, Vol. 36, No. 3, pp. 536-547, (2006).

6. C. Andrade and C. Alonso, On-site measurements of corrosion rate of reinforcements, Construction and building materials, Vol. 15, No. 2-3, pp. 141-145, (2001).

7. M. Curioni, F. Scenini, T. Monetta and F. Bellucci, Correlation between electrochemical impedance measurements and corrosion rate of magnesium investigated by real-time hydrogen measurement and optical imaging, Electrochimica Acta, Vol. 166, pp. 372-384, (2015).

8. A. Jindal and M. Liu, Networked computing in wireless sensor networks for structural health monitoring, IEEE/ACM Transactions on Networking, Vol. 20, No. 4, pp. 1203-1216, (2011).

9. V. G. M. Annamdas and P. Rizzo, Influence of the excitation frequency in the electromechanical impedance method for SHM applications, Smart Sensor Phenomena, Technology, Networks, and Systems, International Society for Optics and Photonics Vol. 7293, (2009).

10. O. Avci, O. Abdeljaber, S. Kiranyaz, M. Hussein, M. Gabbouj and D. J. Inman, A review of vibration-based damage detection in civil structures: From traditional methods to Machine Learning and Deep Learning applications, Mechanical systems and signal processing, Vol. 147, pp. 107077, (2021).

11. C. K. Soh, K. K.Tseng, S. Bhalla and A. Gupta ,Performance of smart piezoceramic patches in health monitoring of a RC bridge, Smart materials and Structures, Vol. 9, No. 4, pp. 533, (2000).

12. W. Yan, W. Q. Chen, C. W. Lim and J. B. Cai, Application of EMI technique for crack detection in continuous beams adhesively bonded with multiple piezoelectric patches, Mechanics of Advanced Materials and Structures, Vol. 15, No. 1, pp. 1-11, (2008).

13. D. Y. Chowdary and M. Alapati, Effect of external vibrations on Electro-Mechanical impedance 
signatures in damage detection, Materials Today, Proceedings, Vol. 45, pp. 3398-3403, (2021).

14. S. Bhalla andC. K. Soh, Structural health monitoring by piezo-impedance transducers. I: Modeling, Journal of Aerospace Engineering, Vol. 17, No. 4, pp. 154165, (2004).

15. C. Bharathi Priya, N. Gopalakrishnana and A. Rama Mohan Rao, Impedance based structural health monitoring using serially connected piezoelectric sensors.

16. C. Zhang, X. Yu, L. Alexander, Y. Zhang, R. Rajamani and N. Garg, Piezoelectric active sensing system for crack detection in concrete structure, Journal of Civil Structural Health Monitoring, Vol. 6, No. 1, pp. 129-139, (2016).

17. C. Liang, F. Sun and C. A. Rogers, Electromechanical impedance modeling of active material systems, Smart Materials and Structures, Vol. 5, No. 2, pp. 171, (1996).

18. V. P. Pavelko, S. Kuznetsov, I. Ozolinsh and I. Pavelko, Some applications of electromechanical impedance technology for SHM, Proceedings of 11th European Conference on Non-Destructive Testing, Prague, Czech Republic, (2014).

19. J. Sowjanya and M. Alapati, Influence of Patch Location on Damage Detection of Smart Bar using EMI Technique, i-Manager's Journal on Civil Engineering, Vol. 9, No. 2, pp. 62, (2019).

20. S. Bhalla, C. K. Soh,K. K. H. Tseng and A.S.Naidu, Diagnosis of incipient damage in steel structures by means of piezoceramic patches, Proceedings of 8 th East Asia-Pacific conference on structural engineering and construction, pp. 5-7, (2001).

21. W. Yan, W. Q. Chen, C. W. Lim and J. B. Cai, Application of EMI technique for crack detection in continuous beams adhesively bonded with multiple piezoelectric patches, Mechanics of Advanced Materials and Structures, Vol. 15, No. 1, pp. 1-11, (2008).

22. W. J. Staszewski, B. C. Lee and R. Traynor, Fatigue crack detection in metallic structures with Lamb waves and 3D laser vibrometry, Measurement Science and Technology, Vol. 18, No. 3, pp. 727, (2007).

23. M. A. Mahmud, A. Abdelgawad, K. Yelamarthi and Y. A. Ismail, Y, Signal processing techniques for IoTbased structural health monitoring, In 2017 29th International Conference on Microelectronics (ICM), IEEE, pp. 1-5, (2017).

24. C. Harshitha, A. Mallika, C. Naveen kumar, Damage detection of structural members using internet of things (IoT) paradigm, In International Conference on Advanced Materials Behavior and Characterization, Vol. 43, No. 2, pp. 2337-2341, (2021).

25. T.Srinivas and M. Abinay Raj, Int. J. of Eng.and Adv. Tech. (IJEAT), ISSN: 2249 - 8958, Volume-8 Issue-6 (2019)

26. T.srinivas and P. Manoj Anand, Int. J. of Innov. Tech. and Explor. Eng.g (IJITEE), ISSN: 22783075, Volume-8 Issue-12 (2019)

27. T.Srinivas and G. Sukesh Reddy, Int. J. of Eng.and Adv. Tech. (IJEAT), ISSN: 2249 - 8958, Volume-9 Issue-1 (2019)

28. T.Srinivas and R. N. Koushik, Int. J. of Innov. Tech. and Explor. Eng.g (IJITEE), ISSN: 22783075, Volume-8 Issue-12 (2019), PP 112-117.

29. K. Sai Gopi, Dr. T. Srinivas and S. P. Raju V, E3S Web of Conferences ICMED 184, 01084GRIET, 28-29 February, https://doi.org/10.1051/e3sconf/2020184011084( 2020)

30. Jagannadha Kumar, M.V., Jagannadha Rao, K., Dean Kumar, B., Srinivasa Reddy, V., Int. J. of Civil Eng. and Tech., 9(7), pp. 1133-1141 (2018)

31. Ganta, J.K., Seshagiri Rao, M.V., Mousavi, S.S., Srinivasa Reddy, V., Bhojaraju, C., Structures 28, pp. 956-972 (2020)

32. Naidu, K.S.S.T., Rao, M.V.S., Reddy, V.S., Int. J. of Innov. Tech. and Explor. Eng.g (IJITEE), 8(9 Special Issue 2), pp. 641-642 (2019)

33. Chandana Priya, C., Seshagiri Rao, M.V., Srinivasa Reddy, V., Int. J. of Civil Eng. and Tech., 9(11), pp. 2218-2225 (2018)

34. Satya Sai Trimurty Naidu, K., Seshagiri Rao, M.V., Srinivasa Reddy, V., Int. J. of Civil Eng. and Tech., 9(11), pp. 2383-2393 (2018)

35. Supriya, Y., Srinivasa Reddy, V., Seshagiri Rao, M.V., Shrihari, S., Int. J. of Rec. Tech. and Engi., 8(3), pp. 5381-5385 (2019)

36. Kotkunde, N., Krishna, G., Shenoy, S.K., Gupta, A.K., Singh, S.K. International Journal of Material Forming, 10 (2), pp. 255-266 (2017)

37. Govardhan, D., Kumar, A.C.S., Murti, K.G.K., Madhusudhan Reddy, G. Materials and Design, 36, pp. 206-214. (2012)

38. Kumar, P., Singhal, A., Mehta, S., Mittal, A. Journal of Real-Time Image Processing, 11 (1), pp. 93-109. (2016)

39. Raghunadha Reddy, T., Vishnu Vardhan, B., Vijayapal Reddy, P. International Journal of Applied Engineering Research, 11 (5), pp. 30923102 (2016)

40. Hussaini, S.M., Krishna, G., Gupta, A.K., Singh, S.K. Journal of Manufacturing Processes, 18, pp. 151-158 (2015) 